\title{
WORKSHOP ON THE SOURCES, QUANTIFICATION AND HEALTH IMPLICATIONS OF BIOAEROSOLS WORKSHOP REPORT
}

\author{
${ }^{1}$ Karen Exley, ${ }^{1}$ Sarah Robertson, \\ ${ }^{2}$ Francis D. Pope, ${ }^{2,3}$ Roy M. Harrison and ${ }^{1}$ Timothy W. Gant \\ ${ }^{1}$ Centre for Radiation, Chemical and Environmental Hazards, \\ Public Health England, Harwell Campus, Oxfordshire \\ ${ }^{2}$ School of Geography, Earth and Environmental Sciences, University of Birmingham, \\ ${ }^{3}$ Department of Environmental Sciences/Centre of Excellence in Environmental Studies, \\ King Abdulaziz University, PO Box 80203, Jeddah, 21589, Saudi Arabia
}

Received 2014-07-14; Revised 2014-09-17; Accepted 2014-09-19

\begin{abstract}
Scientists, health care professionals and the general public have all raised concerns about the potential health impact natural and manmade sources bioaerosols. In response in september 2012 the Natural Environmental Research Council and public health England jointly funded a workshop to review the 'sources, quantification and health implications of bioaerosols'. The organising committee for the workshop identified five priority areas-(1) bioaerosol identification and quantification methodology, (2) bioaerosol sources, (3) health effects of bioaerosols, (4) extreme events, risk assessment and mediation and (5) bioaerosol dispersion and modelling. The primary purpose was to bring together experts to report on recent research and identify research gaps where increased knowledge would improve risk understanding and public health. This report summarises the presentations, the main discussion points and key conclusions that emerged during the workshop.
\end{abstract}

Keywords: Bioaerosols, Health, Dispersion, Modelling

\section{INTRODUCTION}

Bioaerosols are airborne viable and non-viable biological particles (e.g., fungi, bacteria, pollen and viruses), their fragments and by-products. Although bioaerosols are ubiquitous in all environments, the concentration and composition of bioaerosols emitted from natural sources (e.g., animals, man, soil, plants and fungi) depends on several factors, including geographic location, weather, season and time of day (Bertolini et al., 2013; Brodie et al., 2007; Fierer et al., 2008; Lee et al., 2010). There has been sufficient evidence, for example, that warm, damp and humid conditions promote the survival and growth of fungi (mold) in the indoor environment. Several species in the genera Alternaria, Aspergillus, Penicillium and Cladosporium have been reported in studies of molddamaged buildings (Andersen et al., 2011; Polizzi et al., 2009). It has become increasingly recognised that the allergenic and pathogenic potential of fungi is highly dependent on the species within a genus. However, species-level resolution is extremely challenging given the diversity and large number of species. For example the genus Alternaria in cludes approximately 300 species (Seifert and Gams, 2011). In addition to natural sources, bioaerosols may originate from human activities, such as Public Health England, Harwell Campus, Oxfordshire, Tel.: 01235 825173, Fax: 01235833891 
industry, farming, waste disposal and agriculture. In recent years there has been a strong shift towards more sustainable waste disposal practices, such as composting and recycling, particularly following the adoption of the European Union (EU) landfill directive (1993/31/EC). Under the landfill directive, targets have been set to reduce the amount of biodegradable municipal waste being sent for disposal to landfills to $75 \%$ of 1995 levels by 2020. However, a consequence of this transition towards more sustainable forms of waste management has been increasing concern about the potential health risks associated with bioaerosols emitted from composting sites. The complexity associated with the evidence based regulation of bioaerosols was articulated in the workshop with the presentation of Dr Rob Kinnersley who outlined the challenges faced by the environment agency in regulating bioaerosols from composting and intensive farming sites. Major knowledge gaps in hazard characterisation and exposure assessment, however, have made it difficult to carry out an objective evaluation of risk. Furthermore there needs to be a consideration of the future effects of climate change on the bioaerosol exposure. Increases in the intensity and frequency of extreme weather events and consequently to impacts on bioaerosol dispersion have already been observed (D'Amato et al., 2013; Gioulekas et al., 2004). However, to address these concerns it is clear that much greater understanding of exposure is required and for this improved methods to quantitatively and qualitatively analyse bioaerosol samples are needed.

On September 13/14, 2102 the Natural Environmental Research Council (NERC; an executive non-departmental public body in Britain; Polaris House, North Star Avenue, Swindon, SN21EU, UK) and Health Protection Agency (now; Public Health England; Chilton, Didcot, Oxon, OX11 0RQ, UK) jointly funded the first ever dedicated workshop to review the 'sources, quantification and health implications of bioaerosols at the University of Birmingham. Spread over one and a half days, this workshop consisted of presentations by invited speakers as well as small break-out group discussions on focussed topics related to bioaerosols. There were five main areas of focus during the workshop: (1) Bioaerosol sampling and quantification methodology, (2) bioaerosol sources, (3) health effects of bioaerosols, (4) extreme events, risk assessment and mediation and, (5) aerosol dispersion and modelling. The overall objective of this UK-based workshop was to bring together leading UK experts from academia, government and industry to report on the most recent research findings and to identify knowledge gaps where future research is needed. There were also a number of talks from researchers and academics from across Europe since the issues that surround bioaerosols in the UK are most likely to be of relevance to all European Countries. The following report summarises the discussions and conclusions from each of the five themes and outlines the main concerns and challenges identified by attendees that must be addressed.

\section{MEETING REVIEW AND DISCUSSION}

\subsection{Bioaerosol Sampling and Quantification Methodology}

For the analysis and precise quantification of bioaerosols, it is first important to obtain bioaerosol samples that accurately represent the wider environment from which they were taken. There are presently no standardised methods for bioaerosol sampling. Martin Gallagher (University of Manchester) and Alan Bennett (Health Protection Agency) gave presentations on the various sampling methods that can be used to collect air samples from bioaerosol sites and the evolution of these methods over many years. Before deciding on a method of air sampling it is necessary to consider the type of biological species that it is desired to detect as this will likely influence the choice of the air sampler. For example it may be necessary to have some prior information on the likely concentration range, the size of the particle and whether it will remain viable in the collection process if post collection culture is required and the volume of air it will be required to sample. Four commonly used bioaerosol sampling methods are; (1) impactors where the sample is collected onto a solid surface such as a culture plate, (2) impingers where the sample is collected into a liquid, (3) cyclone samplers where the sample is collected dry and, (4) filter samplers which as the name suggest filter particles from the air (Gandolfi et al., 2013; Williams et al., 2013). While their physical and biological collection properties differ considerably, all bioaerosol samplers have one thing in common: None of them are capable of fully capturing all bioaerosol species. For that reason all four samplers are most certainly likely to qualitatively and quantitatively underestimate the actual numbers of bioaerosols. Attendees repeatedly emphasised a pressing need to 
address concerns about sample integrity during collection, transportation and storage and the necessity for longer sampling times and increase in the number of samples. As concentration levels of bioaerosols can vary dramatically there is also a need for better understanding of the effect environmental factors may have on sample efficiency. Finally, once the sample is collected then there is the challenging task of identifying the species present in the samples.

Catherine pashley (University of Leicester) provided an overview of the various methods for the analysis of fungal species in collected samples. Traditionally this has been based on the microscopic analysis of spore trap samples or culture analysis. Apart from being timeconsuming, labour intensive and expensive, results obtained by culture methods represent only a small fraction of the total bioaerosol diversity found in a given environment (Gandolfi et al., 2013). Furthermore bioaerosols not viable or culturable under the imposed media conditions will not be detected, thus producing a potential underestimate or distorted picture of the health impact of bioaerosol exposures. Microscopy based methods suffer many of the same limitations in being laborious, time consuming and prone to human error, as well as analysis being limited to those species that are easily distinguished by their appearance (Gandolfi et al., 2013).

Efforts to improve our understanding of the health risks of bioaerosol exposures have therefore focussed on developing new molecular approaches capable of identifying bioaerosols regardless of their viability or appearance. In developing new methods the focus has first been on techniques that qualitatively improve the qualitative recognition of fungal species, followed by quantification. Particular attention has been given to developing high-throughput molecular techniques, such as High Throughput Sequencing (HTS) and microarrays. All these methods take advantage of genome sequence variation within large repeat arrays, such as ribosomal DNA (rDNA) to differentiate fungi at the species level. Three regions of the fungal genome have potentially sufficient diversity amongst species to allow their use in species recognition and quantification (for a detailed review see (Lindahl et al., 2013)). These are the Internal-Transcribed Spacer (ITS) regions and the Large Subunit (LSU) regions (Fig. 1). These regions can be amplified across species by virtue of the conserved parts of the genome between them.

Generally molecular methods for fungal identification that employ diversity of these regions rely on amplification of the sample, followed by either Sanger-clone based sequencing, hybridisation to specific probes or HTS methods to analyse the regions. Sangersequencing strategies have been successfully used by Pashley et al. (2012) and others (Robertson et al., 2013) for accurate fungal identification. However, this method is laborious, requiring the picking of multiple clones followed by ligation of the amplification product into a suitable vector, making it unsuitable for routine monitoring. Another method that has been explored is amplification of products from these gene regions followed by hybridisation to specific probes anchored in a microarray format. Preliminary data (unpublished) from Pashley and Gant has shown some utility in this method. However, the level of diversity in the fungal genome is low with often only a few single nucleotide changes between species. This renders the design of specific probes very challenging, particularly when they require similar hybridisation characteristics in order to be located on the same microarray for co-hybridisation. Preliminary data indicates the method may be suitable for genus identification where there is more diversity in the genome sequences but difficult for the species level where there is likely a high potential for the missidentification of species. Finally further deployment of the method will be limited by its cost.

The cost effectiveness of HTS methods has led to this being the preferred option for the molecular identification of fungal species. It does not suffer from the problem of a requirement for cloning and picking of the amplified products and does not require complex probe design and hybridisation. It does though require careful optimisation of the bioinformatic pipeline for the data to ensure that the correct species are being identified and in the correct diversity. Application of this methodology for bacterial sequencing utilising the $16 \mathrm{~S}$ ribosomal sub unit region (Janda and Abbott, 2007) suggests that this is the method of choice and several groups are now actively involved with development on several HTS platforms. Initial application to defined samples has shown substantial utility (Brown et al., 2013; Tonge et al., 2013). This method holds the greatest promise for the qualitative assessment of fungal species in bioaerosols, but quantisation will require further development. The reasons for this are that these regions of the fungal genome are present in multiple copies and the spores themselves are multicellular. It will be necessary to determine copy number and cells per spore for each species of interest in order for HTS methods to develop into quantitative tools. 


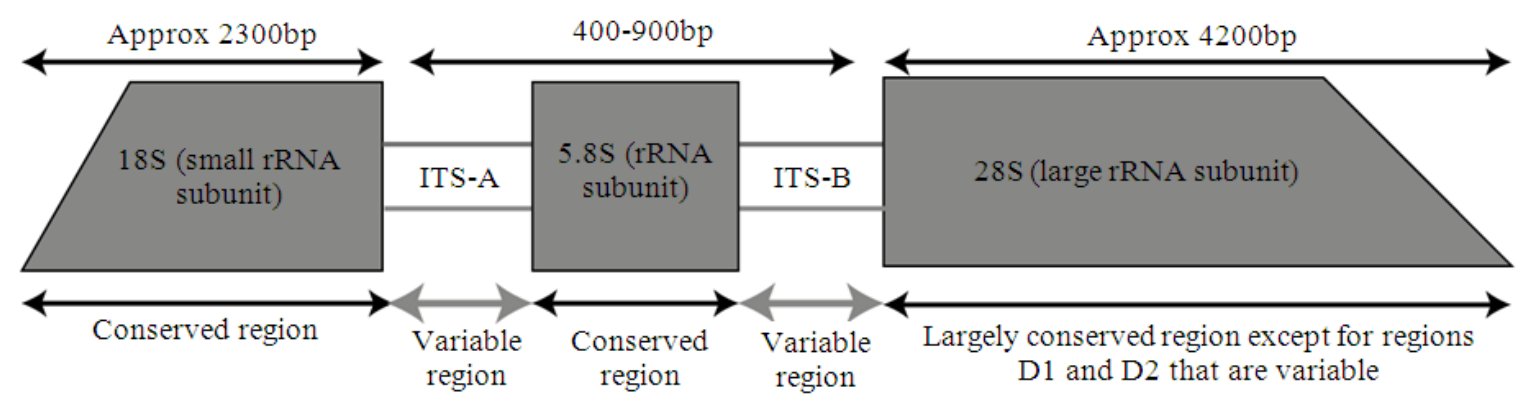

Fig. 1. Variable regions of the fungal genome

It is not just speciation that is important in associating adverse health effects with bioaerosols but also the amount of the allergenic macromolecule in the sample and mycotoxins. The all ergenicity of a bioaerosol is dependent not only on the species distribution and quantity in the sample but also the conditions under which growth has taken place as the expression of allergenic proteins can alter depending on the environmental conditions in which growth occurs. Analysis of these molecules using mass spectral approaches was covered in some detail by Lennart Larsson of the Lund University, Sweden. Dr Larsson demonstrated how mass spectral approaches can be used to detect proteins, carbohydrates and lipids in these samples and also how this approach can be applied to molecular epidemiological studies to examine associations between particular fungal molecules and adverse health outcomes.

The approaches outlined by Drs Pashley and Larsson applied to samples offer substantial benefits to molecular epidemiology and opportunities for causation to be established between fungal species, allergenic molecules and adverse health outcomes.

\subsection{Bioaerosol Sources}

Three areas of bioaerosol source were explored at the workshop; indoor air, outdoor air and occupational exposure that can encompass both indoor and outdoor exposure. These were explored separately by three speakers; Malcolm Richardson (University of Manchester) dealt with the topics of indoor mold, actinobacteria and allergy, Brian Crook (Health and Safety Laboratory UK) addressed outdoor air sources and composting and Wijnand Eduard (National Institute of Occupational Health, Oslo) occupational exposure. In all three of these areas there was an obvious need for more research due to some fundamental deficiencies in understanding. In particular, the workshop presentations highlighted the crucial need to support and fund research activities on indoor mold to address the recognised health risks and associated public concern. Indoor mold affects not only surfaces in the building but furnishings and air quality. In particular there is a challenge with damp affected buildings and a number of pathogenic fungi have been detected in air collected from moisture affected buildings. While studies have reported ill effects in relation to indoor mold exposure, further research is needed to better establish the causative species and allergenic proteins resulting in the health effects. Indoor mold affects not only buildings of poor quality but also those affected by flooding events. Furthermore, it has recently become apparent that modern buildings designed to retain heat and save energy can present an environment that encourages indoor mold growth. Indoor molds grow at lower humidity and temperature levels than are required for bacteria (Gravesen, 1979). This means they are particularly well suited to growing in the indoor environment. Reports indicate the prevalence of indoor damp in Europe and North America to be 10-50\% (WHO, 2009). Others have estimated the figure closer to $20 \%$ (WHO, 2009). In either case this represents a substantial amount of occupied living space. Moreover, as described previously there currently are no standardised methods for assessing bioaerosol species and exposure, making interpretation of existing data difficult, particularly across studies. For indoor mold health effects the strongest link so far established is that inhaling mold spores in residential or occupational settings may cause allergic reactions (Engvall et al., 2001; Fung et al., 2003; Karvala et al., 2008). Other studies have also suggested a potential link between exposure to mold spores, including many Aspergillus species and the prevalence of asthmaand respiratory infections (Denning et al., 2006; Moorman et al., 2011; Mortensen et al., 2011). Finally, despite the fact that myocotoxins and other fungal metabolites are known to 
be toxic, there is very little published information about whether these metabolites are responsible for the health effects reported by individuals in mold-damaged buildings. There is clearly a great deal more work that needs to be done in this area and quite urgently in relation to modern building design and the increasing occurrence of flooding events.

In recent years there has been a substantial increase in composting activity for organic waste driven by a need to reduce the amount of such waste being deposited in landfill sites. Speakers and participants at the workshop discussed the challenges and barriers to implementing policies and measures regarding bioaerosol emissions from composting sites. Bioaerosols generated from the handling and processing of composted organic material pose a potential health risk not only to the workers, but also to nearby residents (see section 3, 'health effects of bioaerosols'). There exists considerable uncertainty over exposures to bioaerosols from composting both for workers and the public and therefore difficulties in decision making to manage any risk. Part of this uncertainty stems from an overall lack of understanding associated with the difficulties mentioned above in the identification and quantification of fungal species. This has caused difficulties in conducting some research, particularly molecular epidemiological research, on the health effects of compost bioaerosols.

In addition to the diversity of organisms there is a further challenge of secondary metabolites in the bioaerosols emitted from composting facilities and the diversity of the expression of allergenic proteins in the same fungal species that may differ depending on the growing environment. Moreover all sites are different and have to be assessed individually. The concentration and composition of bioaerosols emitted from composting sites will depend on a number of site specific factors, such as the type of waste, scale of operation, the design of composting facility (indoors or outdoors) as well as the stage in the composting process. These factors have generally not been taken into consideration when undertaking the risk assessment of facilities and more research is urgently required to address these needs and assess the risk to health to workers and those living in the vicinity of these facilities. There was interest among many of the participants to develop a source inventory database of bioaerosols, similar to that developed for air pollutant emissions by the United States (US) Environmental Protection Agency (EPA). It was felt that such a database could assist in the determination of bioaerosol risk from all sources.

\subsection{Health Effects of Bioaerosols}

The health effects of bioaerosols were addressed by Debbie Jarvis (Imperial College) and Sherwood Berge (Birmingham Heartlands Hospital). Adverse health effects can be caused by many of the biological species found in bioaerosols. The most common effects are respiratory symptoms including wheeze, dyspnoea, exacerbations of asthma and induction of respiratory disease, sensitisation, allergic rhinitis and rare conditions such as allergic alveoli is and hypersensitivity pneumonitis (WHO, 2009). Referring to the WHO report of 2009 Professor Jarvis made the important point that there is sufficient epidemiological evidence to conclude an association between indoor mold and asthma but not enough to prove causation. Epidemiological intervention studies indicate that dampness and associated indoor mold exacerbate asthma in children (Mendell et al., 2011). Professor Burge addressed the adverse health effects of bioaerosol exposure in occupational settings including sick building syndrome, metalworking and refuse workers. The highest incidence of asthma associated with occupational exposure has to date been in metal workers and was correlated with a change in composition of the metal working fluid from an oil-based solution to a water-in-oil emulsion that encouraged bioaerosols. Whilst demonstrating a positive association, the causal organism has yet to be identified. Professor Burge made the point that the lack of facilities in clinical laboratories for the detection of non-pathogenic organisms makes the molecular epidemiology and analysis of patient samples for allergenic species challenging.

For some bioaerosols the health related effect is not allergenic but resembles influenza-like illnesses, for example, Legionnaires' disease, a potentially fatal form of pneumonia caused by legionella bacteria, spread via water droplets suspended in air often from enclosed water systems (Bennett et al., 2013) and Q fever, which starts as an influenza-like illness, caused by the bacterium Coxiella burnetii, widespread among livestock. A population outbreak can occur by inhalation of contaminated dust or contact with infected tissues, such an outbreak occurred in the Netherlands from 2007-2010 due to infected goats on a farm (Van der Hoek et al., 2012).

After metal workers the occupational setting most associated with bioaerosol induced allergenic adverse health effects is farming. The norwegian farmers study found acute symptoms such as eye and nasal irritation were associated with occupational exposure to 
endotoxins and fungal spores; chronic exposures from fungal spores and ammonia were associated with nonatopic asthma and many bioaerosol agents were found to be associated with chronic bronchitis and effects on lung function (Eduard et al., 2001; 2009). Brian Crook (Health and Safety Laboratory) summarised the main components of bioaerosols at commercial composting sites from bacteria (mainly Gram-negative), fungi (mainly Aspergillus fumigatus), end toxins and parasitic protozoa with potential health effects such as those described above for individuals working at these sites but noted that individuals not occupationally exposed were less likely to be at risk (Domingo and Nadal, 2009). In the UK, the environment agency is responsible for regulation of these sites and notes that there is currently limited research on the health effects for the local communities living near composting site. However the consensus from various studies is that bioaerosols from composting activities decline rapidly within the first 100 metres from a site and generally decline to background levels within 250 metres (EA, 2010).

Evidence suggests that indoor mold is associated with respiratory symptoms such as increased asthma development and exacerbation, dyspnoea, wheeze and respiratory infections (Tonge et al., 2013). During the workshop, Malcolm Richardson (University of Manchester) explained how inhalation of spores and toxic volatile metabolites, produced by filamentous fungi, action bacteria and thermoactinomycetes leads to irritation and non-specific symptoms in sensitive persons. Exposure during infancy to specific molds associated with damp has been associated with childhood asthma at seven years of age (Reponen et al., 2012). Whereas, more general increased microbial exposure early in life might be considered protective as studies have shown children who experienced a range of microbial exposures have lower prevalence of asthma and atopy (Douwes et al., 2006; Ege et al., 2011).

Despite the information from occupational and indoor studies, fundamental questions still remain with regards to the health effects of bioaerosols. Attendees agreed that there is insufficient knowledge about health risks associated with specific species and the variation in human health responses. Those who are at risk from developing health effects after bioaerosol exposures include those with pre-existing respiratory disease, children, the elderly and those with impaired immune systems. However there is wide variability in individual susceptibility to bioaerosol exposure. To understand this variability more needs to be understood about the penetration of the bioaerosols in the human respiratory tract, the immune response and how genetic variation may influence an individual's response.

In order to understand the incidence of adverse health outcomes associated with bioaerosols we need to be able to relate the health response to exposure. The development of standardised, objective measure of exposure and effect are required. These should be easy to operate, cheap, high throughput and suitable for use in large scale epidemiological studies. Biological sampling, such as, skin prick and blood sample tests for markers of immunity ( $\mathrm{IgG} / \mathrm{IgE}$ or $\mathrm{CD} 14)$, or even the use of less invasive samples such as tears to measure immunological responses need to be developed and validated.

Epidemiological studies also need to be designed to include qualitative and quantitative measures of multiple bioaerosol agents so that data can be collected on exposures and responses to assist with risk assessment, to guide treatment and to enable cost-benefit analysis for the development of policy for prevention and remediation. Such practical actions are well established for indoor air but more research is needed to address outdoor air exposures.

\subsection{Extreme Events, Risk Assessment and Mediation}

Climate change is expected to cause more frequent occurrences of extreme weather events such as increases in flooding, thunderstorms and temperature rises. These events are likely to lead to changes in bioaerosol type as the environmental conditions impact the growth of species differently and their expression of allergenic macromolecules. Therefore these events could result in new pollen and fungi sensitizations causing an increase in cases of respiratory allergy (Kennedy and Smith, 2012). For example flooded properties, once the waters have receded, present an ideal environment especially in warmer climates for increased indoor mold growth. For example studies of homes undergoing renovation after hurricane Katrina showed high levels of Penicillium, Aspergillus and Paecilomyces (Chew et al., 2006).

Increases in temperature may encourage the growth of different plants species including those known to have allergenic properties, for example, varieties of ragweed, which are associated with increased prevalence of allergic reactions and asthma. Earlier and longer pollination seasons are also likely to occur causing more pollen to be produced and released over longer periods increasing the duration of symptoms for sufferers (Kennedy and Smith, 2012). Extreme weather events, particularly thunderstorms, can induce severe asthma 
attacks in a subgroup of asthmatics (D'Amato et al., 2005). This may, in part, be explained by the close temporal association between the arrival of a thunderstorm, a rise in airborne pollen concentrations and the onset of asthmatic symptoms (Marks et al., 2001). There is also the possibility that pollen grains in the humid conditions of the thunderstorm rupture leading to a greater release of their cytoplasmic content which contain the allergenic proteins (D'Amato et al., 2005).

Particulate Matter (PM), Ozone $\left(\mathrm{O}_{3}\right)$ and other air pollutants are associated with effects on respiratory health (as well as on cardiovascular health) and exposure to both air pollutants and pollen may exacerbate respiratory symptoms of allergy. Gennaro D'Amato (University of Naples) explained that binding of air pollutants to pollen grains, or other plant-based allergens, can initiate airway inflammatory events, that may lead toincreased airway permeability and increased airway responsiveness to bioaerosols (D'Amato et al., $2005 ; 2011$ ). If the air quality monitoring networks were linked with an extended and improved national pollen network to monitor the changes in pollen type and count, our exposure assessment of these types of interactions would be enhanced.

\subsection{Bioaerosol Dispersion and Modelling}

Three speakers, Jon West (Rothamsted Research), Carsten Ambelas Skjøth (National Pollen and Areobiology Research Unit, University of Worcester) and Ian Hall (Health Protection Agency) addressed modelling and dispersion of bioaerosols. In a risk assessment of adverse health outcomes attributable to bioaerosols an accurate measure of exposure is required. This will encompass both effective sampling and analysis, both of which are challenges as articulated above. In addition to this, however, a necessity is to understand how a bioaerosol is dispersed under different weather conditions from an area source.

The physics governing the dispersion and transport of bioaerosols is similar to that of other aerosol types. Dr Skjøth explained that the main factors that determine dispersion of aerosols from a point source are horizontal wind speed and vertical mixing due to atmospheric turbulence. Bioaerosols are removed from the atmosphere through both dry and wet deposition. Dry deposition is a function of density, shape and size of the bioaerosol (Aylor, 2003). Larger bioaerosols preferentially deposit due to higher settling velocities. Wet deposition occurs 'below cloud' where the bioaerosol is caught by impaction with a falling hydrometeor (rain, hail, snow) or 'in cloud' where the bioaerosol either acts as a cloud condensation nucleus or ice nucleus thereby forming a new hydrometeor. Below cloud wet deposition rates increase with bioaerosol size, whilst in cloud wet deposition rates are more complicated depending on a combination of bioaerosol size and composition (Seinfeld and Pandis, 2012). The detailed microphysics of bioaerosol cloud interactions ispoorly understood (Griffiths et al., 2012; Morris et al., 2011). Clouds can also affect bioaerosol dispersion by suppressing insolation and hence reduce the mixing in the boundary layer. The re-suspension of ground deposited bioaerosols is possible through mechanical action such as strong winds and road traffic induced turbulence. However there has been little research undertaken which assesses this route of bioaerosol dispersion. The relative efficiency of these different processes is critically dependent upon the size of individual organisms, or the particles to which they are attached. Bacteria (ca $1 \mu \mathrm{m}$ diameter) and viruses $(<1$ $\mu \mathrm{m}$ diameter) typically have quite long atmospheric lifetimes, potentially of days, while whole pollen grains (typically $>10 \mu \mathrm{m}$ diameter) are mostly subject to rapid removal, with fungal spores (ca 5-15 $\mu \mathrm{m}$ diameter) behaving in an intermediate fashion.

The particle size, shape and morphology of bioaerosols are not static within the atmosphere. Many bioaerosols are hygroscopic, in that their water content is dependent upon the relative humidity. The typically large size of some bioaerosols and hence higher deposition rates, generally results in the majority of bioaerosols depositing close to their sources. Field measurements of the bioaerosol release from large composting facilities show that the bioaerosol concentration typically falls to background levels within $250 \mathrm{~m}$ of the composting site as a result of dispersion and deposition (Swan et al., 2003). However attendees noted that long range transport of bioaerosols does occur and can be crucially important to the dispersion of pathogens on the global and continental scales (Brown et al., 2002). Modelling studies have shown that bioaerosol concentrations typically have local or regional sources, but intermittently long distance transport from more remote regions can provide significant enhancements to the concentration. Dr Skjøth presented the example of the concentration of Alternaria spores measured in Copenhagen which were shown to result from local crop harvesting in Denmark and more distant regions (Skjøth et al., 2012). Various models exist which can be used to predict the dispersion of bioaerosols. The major difficulty in the use of atmospheric chemistry transport models is correctly describing complex source functions (see section 2) 
which are highly heterogeneous both spatially and temporally (Jones et al., 2004). Future modelling capabilities require information on how bioaerosol source functions adapt to changing climates and global warming (Harrison et al., 2005). Moreover if bioaerosols interact with living creatures via inhalation then the dispersion of the bioaerosol within the respiratory system also needs to be considered. The respiratory system can efficiently filter various aerosol sizes through impaction and diffusion (Van Ertbruggen et al., 2005).

To generate more confidence in the modelling of bioaerosols more field and modelling inter-comparison studies are required. Tracer release measurements would be useful to quantify local point source dynamics, especially if reliable molecular markers could be identified. It is possible that existing data sets of nonbiological materials could be used as bioaerosol surrogates for understanding the dispersal mechanisms. Improved modelling will also allow for better placement of sampling sites and networks.

\section{CONCLUSIONS AND OUTCOMES}

Following the formal presentations four breakout sessions were held at which the most pressing requirements for new and further research were discussed; two particular areas of need were identified. First; to improve the speed, accuracy and reproducibility of bioaerosol sampling and detection methods, using molecular approaches. These methodologies must show major advances over culture based approaches which have limited species coverage and only detect viable organisms. Furthermore, these methods should be designed within the context of application in molecular epidemiological studies where the data generated can be correlated with health outcomes. These molecular epidemiological methods also need to be combined with dispersion modelling so better predictions can be made of the health impacts of bioaerosols whose source may lie some distance away from the sensitive receptor. This knowledge could then be applied, for example, in the determination of the minimum distance appropriate for the separation of bioaerosol generating facilities from residential areas. The studies should also lead on to intervention analyses to determine those measures that are likely to have the most impact in reducing the incidence of allergenic respiratory disease associated with bioaerosol exposure. Secondly, a greater understanding of particulate air pollution and bioaerosol interaction is required to determine whether the combination of these factors has a greater impact on the development or incidence of allergies. These meeting outcomes were sub-sequentially captured in a research call from the National Environment Research Council; Environmental Microbiology and Health with a total value for bioaerosol research in these two areas of $\$ 4.4$ million ( 22.6 million). Projects awarded under this scheme are due to commence in April 2015. The specificity of this funding call to the particular areas of need identified from this workshop is testament to the quality of the workshop and the input from participants.

\section{ACKNOWLEDGMENTS}

This workshop was funded by the Natural Environmental Research Council (NERC; of Polaris House, North Star Avenue, Swindon, SN2 1EU, UK) and Health Protection Agency (of Chilton, Didcot, Oxon, OX11 0RQ, UK). We thank Ms Alison Gowers for her very helpful comments and suggestions during the planning of the meeting.

\section{REFERENCES}

Andersen, B., J.C. Frisvad, I. Sondergaard, I.S. Rasmussen and L.S. Larsen, 2011. Associations between fungal species and water-damaged building materials. Applied Environ. Microbiol., 77: 41804188. DOI: 10.1128/AEM.02513-10

Aylor, D.E., 2003. Rate of dehydration of corn (Zea mays L.) pollen in the air. J. Exp. Botany, 54: $2307-$ 2312. DOI: $10.1093 / \mathrm{jxb} / \mathrm{erg} 242$

Bennett, E., M. Ashton, N. Calvert, J. Chaloner and R.N. Gent et al., 2013. Barrow-in-Furness: A large community legionellosis outbreak in the UK. Epidemiol. Infect., 142: 1763-1777. DOI: 10.1017/s0950268813002483

Bertolini, V., I. Gandolfi, R. Ambrosini, G. Bestetti and A. Franzetti et al., 2013. Temporal variability and effect of environmental variables on airborne bacterial communities in an urban area of Northern Italy. Applied Microbiol. Biotechnol., 97: 65616570. DOI: 10.1007/s00253-012-4450-0

Brodie, E.L., T.Z. DeSantis, J.P. Parker, I.X. Zubietta and G.L. Andersen et al., 2007. Urban aerosols harbor diverse and dynamic bacterial populations. Proceedings of the National Academy of Sciences of the United States of America, (USA' 07), University of California, Berkeley, pp: 299-304. DOI: 10.1073/pnas.0608255104

Brown, J.K. and M.S. Hovmoller, 2002. Aerial dispersal of pathogens on the global and continental scales and its impact on plant disease. Science, 297: 537541. DOI: $10.1126 /$ science. 1072678 
Brown, S.P., M.A. Callaham, A.K. Oliver and A. Jumpponen, 2013. Deep Ion torrent sequencing identifies soil fungal community shifts after frequent prescribed fires in a southeastern US forest ecosystem. FEMS Microbiol. Ecol., 86: 557-566. DOI: $10.1111 / 1574-6941.12181$

Chew, G.L., J. Wilson, F.A. Rabito, F. Grimsley and R.L. Morley et al., 2006. Mold and endotoxin levels in the aftermath of Hurricane Katrina: A pilot project of homes in New Orleans undergoing renovation. Environ. Health Perspect., 114: 18831889. DOI: $10.1289 /$ ehp. 9258

D’Amato, G., C.E. Baena-Cagnani, L. Cecchi, I. AnnesiMaesano and W.G. Canonica et al., 2013. Climate change, air pollution and extreme events leading to increasing prevalence of allergic respiratory diseases. Multidiscip Respir Med., 8: 12-12. DOI: 10.1186/2049-6958-8-12

D’Amato, G., G. Liccardi, M. D'Amato and S. Holgate, 2005. Environmental risk factors and allergic bronchial asthma. Clin. Exp. Allergy, 35: 11131124. DOI: $10.1111 /$ j.1365-2222.2005.02328.x

D’Amato, G., M. Rottem, R. Dahl, M. Blaiss and I. Annesi-Maesano, 2011. Climate change, migration and allergic respiratory diseases: An update for the allergist. World Allergy Organ J., 4: 120-125. DOI: 10.1097/WOX.0b013e3182260a57

Denning, D.W., B.R. O’Driscoll, C.M. Hogaboam, P. Bowyer and R.M. Niven, 2006. The link between fungi and severe asthma: A summary of the evidence. Eur. Respiratory J., 27: 615-626. DOI: 10.1183/09031936.06.00074705

Domingo, J.L. and M. Nadal, 2009. Domestic waste composting facilities: A review of human health risks. Environ. Int., 35: 382-389. DOI: 10.1016/j.envint.2008.07.004

Douwes, J., R. van Strien, G. Doekes, J. Smit and B. Brunekreef et al., 2006. Does early indoor microbial exposure reduce the risk of asthma? The prevention and incidence of asthma and mite allergy birth cohort study. J. Allergy Clin. Immunol., 117: 10671073. DOI: 10.1016/j.jaci.2006.02.002

EA, 2010. Composting and potential health effects from bioaerosols: Our interim guidance for permit applications. Position Statement.

Eduard, W., J. Douwes, R. Mehl, D. Heederik and E. Melbostad, 2001. Short term exposure to airborne microbial agents during farm work: Exposureresponse relations with eye and respiratory symptoms. Occup. Environ. Med., 58: 113-118. DOI: 10.1136/oem.58.2.113
Eduard, W., N. Pearce and J. Douwes, 2009. Chronic bronchitis, COPD and lung function in farmers: The role of biological agents. Chest, 136: 716-725. DOI: 10.1378/chest.08-2192

Ege, M.J., M. Mayer, A.C. Normand, J. Genuneit and G.T.S. Group et al., 2011. Exposure to environmental microorganisms and childhood asthma. N Engl. J. Med., 364: 701-709. DOI: 10.1056/NEJMoa1007302

Engvall, K., C. Norrby and D. Norback, 2001. Asthma symptoms in relation to building dampness and odour in older multifamily houses in Stockholm. Int. J. Tuberculosis Lung Dis., 5: 468-477. PMID: 11336279.

Fierer, N., Z. Liu, M. Rodriguez-Hernandez, R. Knight and M.T. Hernandez et al., 2008. Short-term temporal variability in airborne bacterial and fungal populations. Applied Environ. Microbiol., 74: 200207. DOI: 10.1128/AEM.01467-07

Fung, F. and W.G. Hughson, 2003. Health effects of indoor fungal bioaerosol exposure. Applied Occupat. Environ. Hygiene, 18: 535-544. DOI: 10.1080/10473220301451

Gandolfi, I., V. Bertolini, R. Ambrosini, G. Bestetti and A. Franzetti, 2013. Unravelling the bacterial diversity in the atmosphere. Applied Microbiol. Biotechnol., 97: 4727-4736. DOI: 10.1007/s00253-013-4901-2

Gioulekas, D., C. Balafoutis, A. Damialis, D. Papakosta and D. Patakas et al., 2004. Fifteen years' record of airborne allergenic pollen and meteorological parameters in Thessaloniki, Greece. Int. J. Biometeorol., 48: 128-136. DOI: 10.1007/s00484-003-0190-2

Gravesen, S., 1979. Fungi as a cause of allergic disease. Allergy, 34: 135-154. DOI: 10.1111/j.13989995.1979.tb01562.x

Griffiths, P.T., J.S. Borlace, P.J. Gallimore, M. Kalberer and F.D. Pope et al., 2012. Hygroscopic growth and cloud activation of pollen: A laboratory and modelling study. Atmospheric Sci. Lett., 13: 289295. DOI: $10.1002 /$ asl.397

Harrison, R.M., A.M. Jones, P.D. Biggins, N. Pomeroy and A. Beswick et al., 2005. Climate factors influencing bacterial count in background air samples. Int. J. Biometeorol., 49: 167-178. DOI: 10.1007/s00484-004-0225-3

Janda, J.M. and S.L. Abbott, 2007. 16S rRNA gene sequencing for bacterial identification in the diagnostic laboratory: Pluses, perils and pitfalls. J. Clin. Microbiol., 45: 2761-2764. DOI: 10.1128/JCM.01228-07

Jones, A.M. and R.M. Harrison, 2004. The effects of meteorological factors on atmospheric bioaerosol concentrations--a review. Sci. Total Environ., 326: 151-180. DOI: 10.1016/j.scitotenv.2003.11.021 
Karvala, K., H. Nordman, R. Luukkonen, E. Nykyri and E. Toskala et al., 2008. Occupational rhinitis in damp and moldy workplaces. Am. J. Rhinol., 22: 457-462. DOI: 10.2500/ajr.2008.22.3209

Kennedy, R. and M. Smith, 2012. Climate Change Predictions and Aeroallergens Associated with Pollen Grains and Fungal Spores and Potential Impacts on Human Health. In: Health Effects of Climate Change, Vardoulakis, S. and C. Heaviside, (Eds.).

Lee, S.H., H.J. Lee, S.J. Kim, H.M. Lee and Y.P. Kim et al., 2010. Identification of airborne bacterial and fungal community structures in an urban area by T-RFLP analysis and quantitative real-time PCR. Sci. Total Environ., 408: 1349-1357. DOI: 10.1016/j.scitotenv.2009.10.061

Lindahl, B.D., R.H. Nilsson, L. Tedersoo, K. Abarenkov and H. Kauserud et al., 2013. Fungal community analysis by high-throughput sequencing of amplified markers--a user's guide. New Phytol., 199: 288-299. DOI: 10.1111/nph.12243

Marks, G.B., J.R. Colquhoun, S.T. Girgis, M.H. Koski and N.G. Car et al., 2001. Thunderstorm outflows preceding epidemics of asthma during spring and summer. Thorax, 56: 468-471. DOI: 10.1136/thorax.56.6.468

Mendell, M.J., A.G. Mirer, K. Cheung, M. Tong and J. Douwes, 2011. Respiratory and allergic health effects of dampness, mold and dampness-related agents: A review of the epidemiologic evidence. Environ. Health Perspect, 119: 748-756. DOI: 10.1289/ehp. 1002410

Moorman, J.E., H. Zahran, B.I. Truman, M.T. Molla C. Centers et al., 2011. Current asthma prevalence-United States, 2006-2008. MMWR: Surveill. Summ., 14: 84-86. PMID: 21430629.

Morris, C.E., D.C. Sands, M. Bardin, R. Jaenicke and R. Psenner, 2011. Microbiology and atmospheric processes: Research challenges concerning the impact of airborne micro-organisms on the atmosphere and climate. Biogeosciences, 8: 1725. DOI: $10.5194 / \mathrm{bg}-8-17-2011$

Mortensen, K.L., R.H. Jensen, H.K. Johansen, M. Skov and M.C. Arendrup et al., 2011. Aspergillus species and other molds in respiratory samples from patients with cystic fibrosis: A laboratory-based study with focus on Aspergillus fumigatus azole resistance. J. Clin. Microbiol., 49: 2243-2251. DOI: 10.1128/JCM.00213-11
Pashley, C.H., A. Fairs, R.C. Free and A.J. Wardlaw, 2012. DNA analysis of outdoor air reveals a high degree of fungal diversity, temporal variability and genera not seen by spore morphology. Fungal Biol., 116: 214-224. DOI: 10.1016/j.funbio.2011.11.004

Polizzi, V., B. Delmulle, A. Adams, A. Moretti and S. De Saeger, 2009. JEM Spotlight: Fungi, mycotoxins and microbial volatile organic compounds in mouldy interiors from water-damaged buildings. J. Environ. Monitor., 11: 1849-1858. DOI: 10.1039/b906856b

Reponen, T., J. Lockey, D.I. Bernstein, S.J. Vesper and G. LeMasters et al., 2012. Infant origins of childhood asthma associated with specific molds. J. Allergy Clin. Immunol., 130: 639-644. DOI: 10.1016/j.jaci.2012.05.030

Robertson, C.E., L.K. Baumgartner, J.K. Harris, K.L. Peterson and N.R. Pace et al., 2013. Cultureindependent analysis of aerosol microbiology in a metropolitan subway system. Applied Environ. Microbiol., 79: 3485-3493. DOI: 10.1128/AEM.00331-13

Seifert, K.A. and W. Gams, 2011. The genera of Hyphomycetes-2011 update. Persoonia, 27: 119129. DOI: $10.3767 / 003158511 \times 617435$

Seinfeld, J.H. and S.N. Pandis, 2012. Atmospheric Chemistry and Physics: From Air Pollution to Climate Change. 2nd Edn., John Wiley and Sons, Hoboken, ISBN-10: 111859150X, pp: 1232.

Skjøth, C.A., J. Sommer, L. Frederiksen and U.G. Karlson, 2012. Crop harvest in Denmark and Central Europe contributes to the local load of airborne Alternaria spore concentrations in Copenhagen. Atmospheric Chem. Phys., 12: 11107-11123. DOI: 10.5194/acp-12-11107-2012

Swan, J.R.M., A. Kelsey, B. Crook and E.J. Gilbert, 2003. Occupational and Environmental Exposure to Bioaerosols from Composts and Potential Health Effects: A Critical Review of Published Data. 1st Edn., Health and Safety Laboratory, Sudbury, pp: 106.

Tonge, D.P., J.D. Tugwood, J. Kelsall and T.W. Gant, 2013. The role of microRNAs in the pathogenesis of MMPi-induced skin fibrodysplasia. BMC Genomics, 14: 338-338. DOI: 10.1186/1471-2164-14-338

Van der Hoek, W., G. Morroy, N.H. Renders, P.C. Wever and P.M. Schneeberger et al., 2012. Epidemic Q fever in humans in the Netherlands. Adv. Exp. Med. Biol., 984: 329-364. DOI: 10.1007/978-94-007-4315-1_17 
Van Ertbruggen, C., C. Hirsch and M. Paiva, 2005. Anatomically based three-dimensional model of airways to simulate flow and particle transport using computational fluid dynamics. J. Applic. Physiol., 98: 970-980. DOI: 10.1152/japplphysiol.00795.2004
WHO, 2009. WHO guidelines for indoor air quality: dampness and mould: WHO Regional Office Europe.

Williams, M., B. Lamarre, D. Butterfield, S. Tyrrel and A. Simpson et al., 2013. Defra Project WR 1121 Bioaerosols and odour emissions from composting facilities.

Appendix 1. Delegate list

\begin{tabular}{|c|c|c|c|}
\hline Title & First name & Last name & Organisation \\
\hline Dr & Allan & Bennett & Public Health England* \\
\hline Prof & Sherwood & Burge & Birmingham Heartlands Hospital (NHS) \\
\hline Dr & David & Butterfield & National Physical Laboratory \\
\hline Prof & Ian & Colbeck & University of Essex \\
\hline Dr & Brian & Crook & Health and Safety Laboratory \\
\hline Dr & Gennaro & D'Amato & University of Naples \\
\hline Dr & Wijnand & Eduard & National Institure of Occupational Health, Olso \\
\hline Dr & Karen & Exley & Public Health England* \\
\hline Dr & Virginia & Foot & Defence Science and Technology Laboratory \\
\hline Prof & Martin & Gallagher & University of Manchester \\
\hline Prof & Timothy & Gant & Public Health England* \\
\hline Dr & Toni & Gladding & The Open University \\
\hline Ms & Beverley & Groom & University of Worcester \\
\hline Dr & Ian & Hall & Public Health England* \\
\hline Prof & Anna & Hansell & Imperial College London \\
\hline Prof & Roy & Harrison & University of Birmingham \\
\hline Prof & Dick & Heederik & Utrecht University \\
\hline Prof & Deborah & Jarvis & Imperial College London \\
\hline Dr & Elizabeth & Jones & Natural Environment Research Council \\
\hline Prof & Frank & Kelly & King's College London \\
\hline Dr & Andrew & Kibble & Public Health England* \\
\hline Dr & Rob & Kinnersley & Environment Agency \\
\hline Dr & Lennart & Larson & Lund University \\
\hline Dr & James & Matthews & University of Bristol \\
\hline $\mathrm{Mr}$ & Noel & Nelson & Met Office \\
\hline Dr & Gordon & Nicholls & Public Health England* \\
\hline Ms & Kathy & Nicholls & Environment Agency \\
\hline Dr & Ken & O'Callaghan & Department for Environment, Food and Rural Affairs \\
\hline $\mathrm{Dr}$ & Nick & Osborne & European Centre for Environment and Human Health \\
\hline Dr & Catherine & Pashley & University of Leicester \\
\hline $\mathrm{Dr}$ & $\mathrm{Ji}$ & Ping Shi & Environment Agency \\
\hline Prof & Jonathan & Reid & University of Bristol \\
\hline Prof & Malcom & Richardson & University Hospital of South Manchester \\
\hline Prof & Anthony & Seaton & Univesrity of Aberdeen \\
\hline Dr & Carsten & SkjØth & Aarhus University \\
\hline Dr & Jennifer & Smith & Public Health England* \\
\hline $\mathrm{Mr}$ & Jason & Southgate & Ricardo-AEA \\
\hline Dr & Dominick & Spracklen & University of Leeds \\
\hline Dr & Sean & Tyrrel & Cranfield University \\
\hline Dr & Sotiris & Vardoulakis & Public Health England* \\
\hline Dr & Kerry & Walsh & Environment Agency \\
\hline Prof & Andrew & Wardlaw & University of Leicester \\
\hline Dr & Jonathan & West & Rothamsted Research \\
\hline * For & Protection $A$ & & \\
\hline
\end{tabular}

